\title{
Prevailing Serum Vitamin D Levels among Individuals in South Karnataka
}

\section{Surekha Bhat $\mathbf{M}^{1 *}$, lan Lasrado1, Rajeshwari SG ${ }^{1}$, Arpitha Gururaja ${ }^{2}$, Krishnananda Prabhu² and Pragna Rao ${ }^{2}$}

${ }^{1}$ Department of Biochemistry, Xavier University School of Medicine, The Dutch Caribbean, Aruba

${ }^{2}$ Department of Biochemistry, Kasturba Medical College, Manipal, Karnataka, India

\begin{abstract}
Introduction: Prevalence of vitamin deficiency is very high in India. The aim of the present study was to determine according to age groups, the status of vitamin D among individuals using samples received at clinical biochemistry laboratory.

Materials and methods: The study population was grouped according to gender and age in decades. They were divided into three groups according to serum vitamin $D$ status-NVD (normal serum vitamin $\mathrm{D},>30 \mathrm{ng} / \mathrm{ml}$ ), VDI (vitamin D insufficiency, 20-30 ng/ml), VDD (vitamin D deficiency, $<20 \mathrm{ng} / \mathrm{ml}$ ). Blood was collected in plain vacutainers and serum obtained was used for vitamin $D$ estimation. Results were expressed as percentage of the sub-population in question.

Results: Only $13 \%$ of the total study population was normal, $70 \%$ was vitamin D deficient and $17 \%$ showed vitamin $D$ insufficiency. The prevalence of vitamin $D$ deficiency was very high in all age groups and both genders. In all age groups, there were a higher percentage of females in the vitamin D insufficient and deficient groups. Males recorded higher prevalence of vitamin $D$ deficiency in the 0-10 and 20-30 years age group while females recorded higher prevalence of the vitamin deficiency in the 20-30 years and 30-40 years age group

Conclusion: The prevalence of vitamin $D$ insufficiency and deficiency in the present study was high at all age groups and both genders. Further research needs to be conducted to correlate the changing dietary habits to the alterations in availability of 7-dehydrocholesterol for cutaneous biosynthesis of vitamin $\mathrm{D}$.
\end{abstract}

Keywords: Vitamin D deficiency; Vitamin D insufficiency; Age; Gender

\section{Introduction}

Vitamin D is important in growing children as well as adults for normal bone health. Optimal bone mineral health during childhood safeguards against osteoporosis and susceptibility to fractures in the later years. Evidence from animal studies has suggested that 1,25$(\mathrm{OH})_{2}$ D may have a wider biological role, as it influences cellular proliferation and differentiation of several tissues and also plays a part in immunoregulation [1]. Vitamin D deficiency causes rickets in children and osteomalacia in adults. Vitamin D insufficiency in adults causes myopathy, osteopenia, secondary hyperparathyroidism and osteomalacia [2]. In the last one decade, there has been a surge in research related to vitamin $\mathrm{D}$ deficiency. The sunshine vitamin, the deficiency of which was once considered an epidemic and subsequently believed to be controlled, has made a comeback with ever increasing reports of deficiency which is now considered as a pandemic by some researchers. It is believed that about 1 billion people worldwide have vitamin D deficiency or insufficiency [3]. Seasonal variations in $25(\mathrm{OH})$ $\mathrm{D}$ concentrations have widely been reported even in subtropical locations with sunny weather year-round. This variation in $25(\mathrm{OH})$ $\mathrm{D}$ is likely to be determined by the latitude and climate [4]. In India, since majority of the population lives in areas receiving ample sunlight vitamin $\mathrm{D}$ deficiency was expected to be uncommon. However, recent studies suggest that vitamin $\mathrm{D}$ deficiency is very common in apparently healthy individuals at all age groups and both genders in northern as well as southern India [5-7]. Limited data from northern India on vitamin $\mathrm{D}$ status in pregnant women in all 3 trimesters reveal unexpectedly high prevalence (74-98\%) of hypovitaminosis D [8-10]. Zargar et al. report that overall $76(83 \%)$ of the subjects studied had vitamin D deficiency in Kashmir valley of Indian subcontinent [11]. Studies have also shown that the vitamin D status of urban population is lower than the rural population and this difference has been attributed to dress code, occupation, duration of exposure to sunlight [12-17]. In all the above mentioned earlier studies, although data were obtained from different age groups by different researchers, to the best of our knowledge there were no single studies that considered all age groups to determine the prevalence of vitamin D deficiency. The present study was conducted with the objective of determining according to age groups in decades, the status of vitamin $\mathrm{D}$ among individuals using samples received at the clinical biochemistry laboratory, Kasturba Hospital, Manipal, India.

\section{Materials and Methods}

\section{Subjects}

This study was conducted in Kasturba Medical College Hospital, Manipal. Manipal is a coastal town in the southern part of Karnataka, India (74053'E longitude, $12055^{\prime} \mathrm{N}$ latitude). Serum samples $(\mathrm{n}=1151)$ received at Clinical Biochemistry laboratory from January 2012 to December 2012, for which vitamin D measurement was requested, were included in the study. The age of the subjects ranged from 0-90 years and is reflective of the age groups routinely tested in the laboratory. Informed consent was obtained from all patients and the study design conformed to the ethical standards set by the institutional ethics committee and 1975 Helsinki Declaration. Patient confidentiality was maintained by

${ }^{*}$ Corresponding author: Surekha Bhat M, Department of Biochemistry, Xavier University School of Medicine, Oranjestad, The Dutch Caribbean, Aruba, Tel: 011 2975887766; E-mail: mbhatphd@xusom.com

Received June 23, 2017; Accepted July 28, 2017; Published August 04, 2017

Citation: Surekha Bhat M, Lasrado I, Rajeshwari SG, Gururaja A, Prabhu K et al. (2017) Prevailing Serum Vitamin D Levels among Individuals in South Karnataka. J Bioanal Biomed 9: 201-205. doi:10.4172/1948-593X.1000178

Copyright: @ 2017 Surekha Bhat M, et al. This is an open-access article distributed under the terms of the Creative Commons Attribution License, which permits unrestricted use, distribution, and reproduction in any medium, provided the origina author and source are credited. 
anonymization of the samples received. Only those samples that were from individuals with normal kidney and liver function, as reflected by their urine and serum creatinine as well as Liver Function Test (LFT) values, were used for the study.

Age and gender were the only two variables derived from the dataset and investigated as predictors of vitamin D status. The study population was thus grouped according to gender and age in decades, the minimum range being $0-10$ years and the maximum being $80-90$ years.

To facilitate interpretation of results, the study population was divided into three groups based on their serum 25 hydroxy D status:

1. NVD-Normal Vitamin D (>30 ng/ml).

2. VDI-Vitamin D Insufficiency $(20-30 \mathrm{ng} / \mathrm{ml})$.

3. VDD-Vitamin D Deficiency $(<20 \mathrm{ng} / \mathrm{ml})$.

This division was based on the cut-off points for vitamin D deficiency as defined by the Endocrine Society's practice guidelines [18].

\section{Methods}

Blood samples $(5 \mathrm{ml})$ were collected in plain vacutainers with draw volume $1-10 \mathrm{ml}$, allowed to clot and centrifuged at $3500 \mathrm{rpm}$ for $10 \mathrm{~min}$ to separate serum. All serum samples were analyzed for vitamin $\mathrm{D}$ as soon as they were received in the lab, there were no stored samples. The compound measured for vitamin D activity in the serum was 25 hydroxy D. Serum 25 hydroxy D was determined by electrochemiluminescence based on ELISA. The COBAS 6000 vitamin $\mathrm{D}_{3}$ electrochemiluminescence immunoassay (Roche Diagnostics, Penzberg, Germany) utilizes a competitive assay format based on the streptavidin-biotin technology. The assay employs a polyclonal sheep antibody against $25(\mathrm{OH}) \mathrm{D}_{3}$, which is ruthenium labeled. The vitamin $\mathrm{D}$ in the sample competes for binding with biotinylated $25(\mathrm{OH}) \mathrm{D}_{3}$ antigens which is bound to the strepavidin coated micro particles. Appropriate internal and external quality control was run to ensure accuracy of data.

\section{Statistical analysis}

Data were analyzed using MS Office Excel 2007 and results were expressed as percentage of the sub-population in question.

\section{Results}

Out of the total 1151 individuals included in the study, 384 were males and 767 were females. Only $13 \%$ of the total study population was normal (157 out of 1151-79 males, 78 females). Nearly $70 \%$ of the total study population was vitamin D deficient (798 out of 1151-226 males, 572 females) and $17 \%$ showed vitamin D insufficiency (196 out of 1151-79 males, 117 females). Among males, only 21\% (79 out of 384 ) had normal vitamin D status whereas $58.9 \%$ (226 out of 384 ) had vitamin D deficiency and 20.6\% (79 out of 384) had vitamin D insufficiency. Likewise, among females only $10 \%$ (78 out of 767) had normal vitamin D status, $74.6 \%$ (572 out of 767 ) were vitamin D deficient and $15.3 \%$ (117 out of 767) were vitamin D insufficient.

Table 1 shows the distribution of individuals in the three groups of vitamin D status according to gender and age in decades. When compared among the different age groups, the age groups with a higher percentage of normal vitamin D status were $0-10$ years (5 out of 19 i.e., $26 \%$ ) followed by $60-70,70-80$ and $80-90$ years age group ( $21 \%$ in all 3 groups i.e., 43/210, 20/97, 5/24 respectively). The highest prevalence of vitamin D deficiency was seen in the 20-30 years age group (117 out of $142 ; 82.4 \%$ ) followed by $30-40$ years age group (117 out of $158 ; 74.1 \%$ ). In almost all the age groups, there were more males than females with normal vitamin $\mathrm{D}$ levels and more females than males with vitamin $\mathrm{D}$ insufficiency or vitamin D deficiency (Table 2). As seen in Figures 1 and 2, males recorded higher prevalence of vitamin D deficiency in the $0-10$ and $20-30$ years age group $(71.4 \%$ and $70.5 \%$ respectively) and females recorded higher prevalence of vitamin deficiency in the 20-30 years and $30-40$ years age group ( $87.8 \%$ and $79.8 \%$ respectively). The maximum percentage of individuals in all age groups, among both genders as well as among the study population as a whole, belonged to the vitamin $\mathrm{D}$ deficiency category.

\section{Discussion}

Vitamin D deficiency is now regarded as pandemic by some researchers. Holick and Chen [19] report that both children and adults living in the United States, Europe, Middle East, India, Australia and Asia are affected by vitamin $\mathrm{D}$ deficiency. Studies also suggest that a high percentage of children, adolescents and adults are at risk of vitamin D deficiency $[5-7,20-22]$. In the present study only $13 \%$ of the

\begin{tabular}{|c|c|c|c|c|c|c|c|c|c|}
\hline \multirow{2}{*}{ Age group (years) } & \multicolumn{3}{|c|}{ Overall (n=1151) } & \multicolumn{3}{|c|}{ Males $(n=384)$} & \multicolumn{3}{|c|}{ Females $(n=767)$} \\
\hline & NVD \% & VDI \% & VDD \% & NVD \% & VDI \% & VDD \% & NVD \% & VDI \% & VDD \% \\
\hline $\begin{array}{c}0-10 \\
(n=19)\end{array}$ & 26.32 & 15.79 & 57.89 & 14.29 & 14.29 & 71.43 & 33.33 & 16.67 & 50.00 \\
\hline $\begin{array}{c}10-20 \\
(n=43)\end{array}$ & 13.95 & 20.93 & 65.12 & 20.00 & 20.00 & 60.00 & 8.70 & 21.74 & 69.57 \\
\hline $\begin{array}{c}20-30 \\
(n=142)\end{array}$ & 5.63 & 11.97 & 82.39 & 9.09 & 20.45 & 70.45 & 4.08 & 8.16 & 87.76 \\
\hline $\begin{array}{c}30-40 \\
(n=158)\end{array}$ & 10.76 & 15.19 & 74.05 & 26.47 & 20.59 & 52.94 & 6.45 & 13.71 & 79.84 \\
\hline $\begin{array}{c}40-50 \\
(n=231)\end{array}$ & 10.39 & 19.05 & 70.56 & 20.00 & 21.43 & 58.57 & 6.21 & 18.01 & 75.78 \\
\hline $\begin{array}{c}50-60 \\
(n=227)\end{array}$ & 12.78 & 17.62 & 69.60 & 15.87 & 22.22 & 61.90 & 11.59 & 15.85 & 72.56 \\
\hline $\begin{array}{c}60-70 \\
(n=210)\end{array}$ & 20.48 & 16.67 & 62.86 & 25.88 & 20.00 & 54.12 & 16.80 & 14.40 & 68.80 \\
\hline $\begin{array}{c}70-80 \\
(n=97)\end{array}$ & 20.62 & 20.62 & 58.76 & 21.57 & 21.57 & 56.86 & 19.57 & 19.57 & 60.87 \\
\hline $\begin{array}{l}80-90 \\
(n=24)\end{array}$ & 20.83 & 16.67 & 62.50 & 40.00 & 10.00 & 50.00 & 7.14 & 21.43 & 71.43 \\
\hline
\end{tabular}

NVD: Normal Vitamin D Status (>30 ng/ml); VDI: Vitamin D Insufficiency (20-30 ng/ml); VDD: Vitamin D Deficiency (<20 ng/ml)

Table 1: Demographic details of the study population. All values are expressed as percentage. 


\begin{tabular}{|c|c|c|c|c|c|c|}
\hline \multirow{2}{*}{ Age group (years) } & \multicolumn{2}{|c|}{ NVD } & \multicolumn{2}{|c|}{ VDI } & \multicolumn{2}{|c|}{ VDD } \\
\hline & Males (\%) & Females (\%) & Males (\%) & Females (\%) & Males (\%) & Females (\%) \\
\hline $0-10$ & 20.00 & 80.00 & 33.33 & 66.67 & 45.45 & 54.55 \\
\hline $10-20$ & 66.67 & 33.33 & 44.44 & 55.56 & 42.86 & 57.14 \\
\hline $20-30$ & 50.00 & 50.00 & 52.94 & 47.06 & 26.50 & 73.50 \\
\hline $30-40$ & 52.94 & 47.06 & 29.17 & 70.83 & 15.38 & 84.62 \\
\hline $40-50$ & 58.33 & 41.67 & 34.09 & 65.91 & 25.15 & 74.85 \\
\hline $50-60$ & 34.48 & 65.52 & 35.00 & 65.00 & 24.68 & 75.32 \\
\hline $60-70$ & 51.16 & 48.84 & 48.57 & 51.43 & 34.85 & 65.15 \\
\hline $70-80$ & 55.00 & 45.00 & 55.00 & 45.00 & 50.88 & 49.12 \\
\hline $80-90$ & 80.00 & 20.00 & 25.00 & 75.00 & 33.33 & 66.67 \\
\hline
\end{tabular}

NVD: Normal Vitamin D Status (>30 ng/ml); VDI: Vitamin D Insufficiency $(20-30 \mathrm{ng} / \mathrm{ml})$; VDD: Vitamin D Deficiency $(<20 \mathrm{ng} / \mathrm{ml})$

Table 2: Gender wise distribution of the study population in the different age groups of the three categories of vitamin $D$ status.

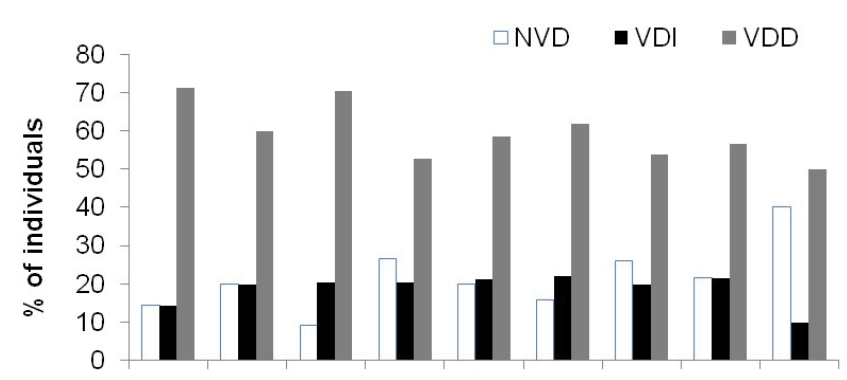

0-10 10-20 20-30 30-40 40-50 50-60 60-70 $70-8080-90$

Figure 1: Distribution of males with normal: Vitamin D (NVD; $>30 \mathrm{ng} / \mathrm{ml})$; Vitamin D insufficiency (VDI; 20-30 ng/ml); and Vitamin D deficiency (VDD; $<20 \mathrm{ng} / \mathrm{ml}$ ) into different age groups.

subjects had normal vitamin D status and the prevalence of vitamin $\mathrm{D}$ deficiency was very high in all age groups and both genders $(69.3 \%$ overall; $58.9 \%$ in males, $74.6 \%$ in females). The results of the present study support the earlier findings. Although earlier studies in India report vitamin deficiency in both genders and all age groups, each of those studies dealt with one specific age group [5-7]. This study, however, deals with vitamin $\mathrm{D}$ status in all age groups from infancy to old age among both genders.

Rucker et al. [23] note that although frank vitamin D deficiency causes rickets and osteomalacia, identification of vitamin $\mathrm{D}$ insufficiency, which affects bone health, is likely of greater clinical importance. Although in the present study, the prevalence of vitamin $\mathrm{D}$ insufficiency was lower compared to that of vitamin D deficiency in the total study population, at all age groups and in both genders, this prevalence cannot be underestimated since the percentage of individuals in this category was higher than those with normal vitamin D levels in almost all subgroups. Vitamin D insufficiency is known to cause myopathy, osteopenia, secondary hyperparathyroidism and osteomalacia [2]. Patients with osteomalacia often complain of isolated or global bone discomfort along with aches and pains in their joints and muscles and these patients may be misdiagnosed with fibromyalgia [19]. In the background of these reports, the observed high prevalence of vitamin D insufficiency needs to be kept in mind considering the fact that currently there are increasing reports of aches and pains in joints and muscles in Indian hospitals.

The present authors observed a very high prevalence of vitamin $\mathrm{D}$ deficiency $(71.5 \%)$ among males of $0-10$ year's age group. This can be attributed to the fact that the prevalence of vitamin D deficiency is reported to be high during all three trimesters in pregnant women in

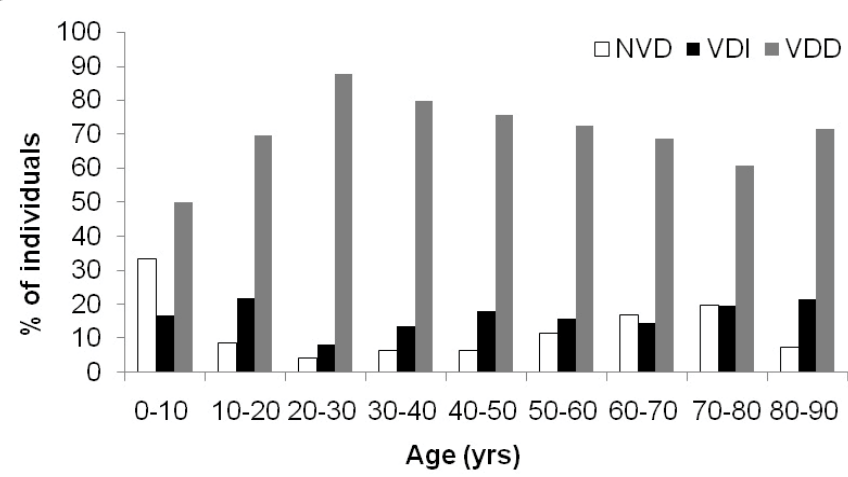

Figure 2: Distribution of females with normal: Vitamin D (NVD; $>30 \mathrm{ng} / \mathrm{ml}$ ); Vitamin D insufficiency (VDI; 20-30 $\mathrm{ng} / \mathrm{ml}$ ); and Vitamin D deficiency (VDD; $<20 \mathrm{ng} / \mathrm{ml}$ ) into different age groups.

India [8-10] and this could manifest in infants at birth and beyond. Some of the previous authors maintain that vitamin $\mathrm{D}$ deficiency in maternal blood correlated with that in cord blood [8]. It has also been discussed by previous authors that vitamin D deficiency manifests with compromised length from birth itself without any potential for catch up growth in view of the fact that vitamin D deficiency continues to afflict even toddlers and school children in India [24]. The present findings of vitamin D status in males at 0 - 10 years age further supports these reports. However the small sample size is a limitation this study, hence further studies with larger cohorts may be conducted to arrive at assertive conclusions regarding vitamin D status in infants and childhood of both genders in the Indian scenario.

Ford et al. [25] have reported widespread vitamin D deficiency in a UK-inner city population, more so in women. The results of the present study support these reports in that females showed a higher prevalence of vitamin D deficiency than males, in the total study population as well as in all age groups. This is an important finding that needs attention particularly in the adults, bearing in mind the fact that low maternal vitamin $\mathrm{D}$ can result in low vitamin $\mathrm{D}$ in new born and have serious pediatric implications. Ford et al. attribute the higher prevalence of vitamin D deficiency in Asian women over Asian men to the type of clothing worn by the former. Asian women tend to wear clothes that cover most of the skin and studies have shown that fully covered dressing style contributes to vitamin D deficiency. In the present study, the higher prevalence of the vitamin deficiency could be due to the type of clothing or the increased use of sunscreens particularly by the female fraternity, because it has been reported that wearing a sunscreen with an SPF of 15 reduces vitamin D synthesis in the skin by $99 \%$ [19]. However, as has been discussed in the end of this section, the present authors also 
wish to draw one's attention to the role of changing dietary habits in determining the vitamin $\mathrm{D}$ status in the current population.

Noteworthy, in the present study, is that there was a higher prevalence of vitamin D deficiency in the middle aged adults than at old age, when the efficiency of vitamin D biosynthesis is believed to decrease due to decreased precursor availability, renal function, decreased renal hydroxylase activity [23]. According to Harinarayan and Joshi [7], it is important to know the vitamin D status in the middle aged group of population (20-45 years) as the peak bone mass is achieved up to 30 years of age and the parity of women and their nutritional status (bone health) determines the pattern of post-menopausal bone loss and age related osteoporosis. Studies by previous authors report a high prevalence of vitamin D deficiency in these age groups [11,26], similar to the findings in the present study.

Most of the previous authors attribute the reason for the very high prevalence of vitamin D deficiency to increased use of sunscreens and a decrease in sun exposure due to changes in lifestyle. Marwaha et al. [27] have reported that mean serum $25(\mathrm{OH})$ D levels were significantly higher in sportswomen when compared to controls among healthy Indian women. However, it has been observed in the same study that inspite of $2 \mathrm{~h}$ of sun exposure and exposure of $30 \%$ body surface area, only $52 \%$ of the sportswomen could achieve serum $25(\mathrm{OH}) \mathrm{D}$ levels beyond $20 \mathrm{ng} / \mathrm{ml}$. Likewise, in a study by the same authors involving military personnel, $85 \%$ of the healthy adult Indian men could not achieve serum $25(\mathrm{OH})$ D levels beyond $20 \mathrm{ng} / \mathrm{ml}$ despite adequate outdoor activities and sun exposure [28]. Hence, the present authors wish to suggest here that changing dietary habits could play an important role in determining the vitamin D status in humans. It is true that a maximum of only ten percent of vitamin $\mathrm{D}$ is obtained from the diet in humans and the rest of it comes from solar UV-induced biosynthesis in the skin [29]. However, one tends to overlook the fact that the precursor for biosynthesis, 7 dehydrocholesterol (7-DHC), is synthesized from cholesterol, which in turn is obtained from the diet. Bogh [30] has reported a positive correlation between $\Delta 25(\mathrm{OH}) \mathrm{D}_{3}$ and the total cholesterol concentration (measured at baseline) following UVB exposure in a subgroup of 28 non-sun worshippers with limited past sun exposure. This calls for further research that looks into not just sun exposure as a causative factor but also changing dietary habits as additional causative factors responsible for the increasing vitamin $\mathrm{D}$ deficiency in the community. An in-depth research into those components of the diet that have a direct bearing on serum total cholesterol namely the type of cooking oil used, could provide vital clues to the role of changing dietary habits in determining vitamin $\mathrm{D}$ status in the present population. Bogh also mentions in the same paper that vitamin $\mathrm{D}$ synthesis begins in the bowel epithelium with an oxidation of cholesterol to 7 dehydro-cholesterol. Studies on alterations of the gut flora, if any, due to changing dietary habits and its effect on the availability of 7 dehydrocholesterol for vitamin D synthesis could throw more light on the cause of the increasing prevalence of vitamin D deficiency.

\section{Conclusion}

In conclusion, the prevalence of vitamin D insufficiency as well as deficiency in the present study was high at all age groups and both genders. The highest prevalence was in infancy and childhood (0-10 years) in males and in the middle aged group in general (20-30 years and $30-40$ years). Further research needs to be conducted to correlate the changing dietary habits to the changes in gut flora and alterations in availability of 7- dehydrocholesterol for cutaneous biosynthesis of vitamin D.

\section{Acknowledgements}

The authors place on record their gratitude to Dr. P Suma Bhat, Statistician and Computational linguist, University of Illinois, Urbana for providing statistical consultation related to this study. The authors are also grateful to $\mathrm{Dr}$. Guruprasad Rao, Professor and Head, Department of Biochemistry, as well as English Language specialist, Melaka Manipal Medical College, Manipal, India and Ms. Kendra Parson, English Language specialist, Xavier University School of medicine, Aruba for proofreading the manuscript for factual, grammatical and vocabulary errors.

\section{References}

1. Maxwell JD (1994) Seasonal variation in vitamin D. Proceedings of the Nutrition Society 53: 533-543.

2. Lips $P$ (2001) Vitamin D deficiency and secondary hyperparathyroidism in the elderly: consequences for bone loss and fractures and therapeutic implications. Endocr Rev 22: 477-501.

3. Hollick MF (2007) Vitamin D deficiency. N Engl J Med 357: 266-281.

4. Bolland MJ, Grey AB, Ames RW, Mason BH, Horne AM, et al. (2007) The effects of seasonal variation of 25-hydroxyvitamin $D$ and fat mass on a diagnosis of vitamin D sufficiency. Am J Clin Nutr 86: 959-964.

5. Harinarayan CV (2005) Prevalence of vitamin D insufficiency in postmenopausa South Indian women. Osteoporos Int 16: 397-402.

6. Marwaha RK, Sripathy G (2008) Vitamin D and bone mineral density of healthy school children in northern India. Indian J Med Res 127: 239-244.

7. Harinarayan CV, Joshi SR (2009) Vitamin D status in India-Its implications and remedial measures. J Assoc Physicians India 57: 40-48.

8. Sachan A, Gupta R, Das V, Agarwal A, Awasthi PK, et al. (2005) High prevalence of vitamin $D$ deficiency among pregnant women and their newborns in northern India. Am J Clin Nutr 81: 1060-1064.

9. Sahu M, Bhatia V, Aggarwal A, Rawat V, Saxena P, et al. (2009) Vitamin D deficiency in rural girls and pregnant women despite abundant sunshine in northern India. Clin Endocrinol (Oxf) 70: 680-684.

10. Marwaha RK, Tandon N, Chopra S, Agarwal N, Garg MK, et al. (2011) Vitamin $\mathrm{D}$ status in pregnant Indian women across trimesters and different seasons and its correlation with neonatal serum 25-hydroxyvitamin $\mathrm{D}$ levels. $\mathrm{Br} \mathrm{J}$ Nutr 106: $1383-1389$

11. Zargar AH, Ahmad S, Masoodi SR, Wani Al, Bashir MI, et al. (2007) Vitamin $\mathrm{D}$ status in apparently healthy adults in Kashmir Valley of Indian subcontinent Postgrad Med J 83: 713-716.

12. Balasubramanian K, Rajeswari J, Gulab GYC, Agarwal AK, Kumar A, et al (2003) Varying role of vitamin D deficiency in the etiology of rickets in young children vs. adolescents in northern India. J Trop Pediatr 49: 201-206.

13. Goswami R, Kochupillai N, Gupta N, Goswami D, Singh N, et al. (2008) Presence of $25(\mathrm{OH}) \mathrm{D}$ deficiency in rural north Indian village despite abundant sunshine. J Assoc Physicians India 56: 755-757.

14. Harinarayan CV, Ramalakshmi T, Prasad UV, Sudhakar D, Srinivasarao PV, et al. (2007) High prevalence of low dietary calcium, high phytate consumption, and vitamin D deficiency in healthy south Indians. Am J Clin Nutr 85: 1062-1067.

15. Harinarayan CV, Ramalakshmi T, Prasad UV, Sudhakar D (2008) Vitamin D status in Andhra Pradesh: a population based study. Indian J Med Res 127: 211-218.

16. Harinarayan CV, Ramalakshmi T, Venkataprasad U (2004) High prevalence of low dietary calcium and low vitamin D status in healthy south Indians. Asia Pac $\mathrm{J}$ Clin Nutr 13: 359-364.

17. Sahu M, Das V, Aggarwal A, Rawat V, Saxena P, et al. (2009) Vitamin D replacement in pregnant women in rural northern India-a pilot study. Eur J Clin Nutr 63:1157-1159.

18. Holick MF (2012) Evidence-based D-bate on health benefits of vitamin D revisited. Dermatoendocrinol 4: 183-190.

19. Holick MF, Chen TC (2008) Vitamin D deficiency: a worldwide problem with health consequences. Am J Clin Nutr 87: 1080-1086.

20. Marwaha RK, Tandon N, Reddy D, Reddy HK, Aggarwal R, et al. (2005) Vitamin $\mathrm{D}$ and bone mineral density status of healthy school children in northern India. Am J Clin Nutr 82: 477-482. 
Citation: Surekha Bhat M, Lasrado I, Rajeshwari SG, Gururaja A, Prabhu K, et al. (2017) Prevailing Serum Vitamin D Levels among Individuals in South Karnataka. J Bioanal Biomed 9: 201-205. doi:10.4172/1948-593X.1000178

21. Gordon CM, DePeter KC, Feldman HA, Grace E, Emans SJ (2004) Prevalence of vitamin $D$ deficiency among healthy adolescents. Arch Pediatr Adolesc Med 158: 531-537.

22. Tangpricha V, Pearce EN, Chen TC, Holick MF (2002) Vitamin D insufficiency among free-living healthy young adults. Am J Med 112: 659-662.

23. Rucker D, Allan JA, Gordon HF, Hanley DA (2002) Vitamin D insufficiency in a population of healthy western Canadians. CMAJ 166: 1517-1524

24. Goswami R, Mishra SK, Kochupillai N (2008) Prevalence \& potential significance of vitamin D deficiency in Asian Indians. Indian J Med Res 127 : 229-238.

25. Ford L, Graham V, Wall A, Berg J (2006) Vitamin D concentrations in an UK inner-city multicultural outpatient population. Ann Clin Biochem; 43: 468-473.

26. Ramakrishnan S, Bhansali A, Bhadada SK, Sharma R, Walia R, et al. (2011)
Vitamin D status and its seasonal variability in healthy young adults in an Asian Indian urban population. Endocr Pract 17: 185-191

27. Marwaha RK, Puri S, Tandon N, Dhir S, Agarwal N, et al. (2011) Effects of sports training \& nutrition on bone mineral density in young Indian healthy females. Indian J Med Res 134: 307-313.

28. Marwaha RK, Tandon N, Shivaprasad C, Kanwar R, Mani K, et al. (2009) Peak bone mineral density of physically active healthy Indian men with adequate nutrition and no known current constraints to bone mineralization. J Clin Densitom 12: 314-321.

29. Holick MF (2005) Vitamin D: Important for prevention of osteoporosis cardiovascular heart disease, type 1 diabetes, autoimmune diseases and some cancers. South Med J 98: 1024-1026.

30. Bogh MKB (2012) Vitamin D exposure after UVB: aspects of UV-related and personal factors. Scand J Clin Lab 72: 24-31. 